\title{
Sports Related Orofacial Injuries: A Review Of 'On-Field Management' By Dentist
}

Sandesh D. Suryawanshi ${ }^{1}$, Sonali G. Kadam ${ }^{2 *}$, Easwaran Ramaswami ${ }^{3}$, Pranoti P. Kausadikar ${ }^{4}$, Bhavana K. Murjani ${ }^{4}$, Reshma Saju ${ }^{4}$, Prachi Mathe ${ }^{4}$

${ }^{1}$ Post-graduate student, Department of Oral Medicine and Radiology, Government Dental College and Hospital, Mumbai, Maharashtra, India.

${ }^{2}$ Professor (Academic), Department of Oral Medicine and Radiology, Government Dental College and Hospital, Mumbai, Maharashtra, India

${ }^{3}$ Associate Professor and Head, Department of Oral Medicine and Radiology, Government Dental College and Hospital, Mumbai, Maharashtra, India

${ }^{4}$ Post-graduate student, Department of Oral Medicine and Radiology, Government Dental College and Hospital, Mumbai, Maharashtra, India

\section{Abstract}

Sports-related dental injuries are very common among athletes. Many of these injuries can lead to permanent damage in their aesthetics, reflecting back on their confidence and performance. It is very important to immediately treat sports-related injuries and hence, prevent future permanent complications. Sporting events in India are organized without appointing a dentist "on the field, " which leads to reduced chances of attending to the orofacial injuries immediately. A good amount of literature is available regarding the management of dental injuries in the dental office. Since there is no information available regarding 'on field' immediate management of these injuries, we have tried to provide collective information regarding immediate management of dental injuries occurring 'on field' by the dental professional.

Keywords: Immediate dental management, On-field dental management, Sports-related dental injuries, Sports orofacial fracture, Tooth avulsion, Tooth fracture.

Int J Eth Trauma Victimology (2021). DOI: 10.18099/ijetv.v7i01.8

\section{INTRODUCTION}

$\mathrm{D}$ ental injuries are one of the most commonly found orofacial injuries in sportspersons. Sports dentistry is the branch of dentistry, which involves the prevention and treatment of orofacial sports injuries and related oral diseases. ${ }^{1}$

There is a higher risk of dental injury in sports that involve direct contact, including boxing, football, cricket, kabaddi, baseball, wrestling, etc. To prevent sport-related oral and facial injuries, the sportsperson should have adequate knowledge regarding the occurrence, severity, and prevention of trauma. But in spite of all these preventive measures, sports players tend to suffer from dental trauma frequently. ${ }^{2}$

Due to the lack of awareness, many athletes are unaware of the health implications of a traumatic injury. In sports, there exists a high potential of incurring severe head and orofacial injuries. Many of these injuries can lead to permanent damage in their aesthetics, reflecting back on their confidence, resulting in emotional stress and adversely affecting their performance. The dentist plays an imperative role in educating athletes, coaches, and patients about the importance of preventing and managing orofacial injuries in sports. Traumatic dental injuries represent $18-30 \%$ of all oral pathologies, and a considerable number of these are sportsrelated. The overall pooled prevalence of dentofacial injuries in combat sports was approximately $30 \%{ }^{3}$ It is very important to immediately treat sports-related injuries and hence, prevent future permanent complications. ${ }^{4,5}$ Sporting events in India are organized

CIJETV. All rights reserved
Corresponding Author: Sonali G. Kadam, Professor (Academic), Department of Oral Medicine and Radiology, Government Dental College and Hospital, Mumbai, Maharashtra, India, e-mail: sonalikdm863@gmail.com

How to cite this article: Suryawanshi SD, Kadam SG, Ramaswami E, Kausadikar PP, Murjani BK, Saju R, Mathe P. Sports Related Orofacial Injuries: A Review Of 'On-Field Management' By Dentist. Int J Eth Trauma Victimology. 2021;7(1):37-40.

Source of support: Nil

Conflict of interest: None

Received: $13 / 04 / 2021$;

Received in revised form: 12/05/2021;

Accepted:20/05/2021;

Published: 25/06/2021

without appointing a dentist "on the field, " which leads to reduced chances of attending to the orofacial injuries immediately.

Many articles have given prevention modalities, in-depth management of dental trauma in the dental office, and creating awareness to sportsmen and coaches for immediate actions to be taken after dental injury, but there is no collective data available about "on immediate field management by the dentist" for dental injuries, occurring due to sports. Also, there is a lack of specific protocol or universal guidelines in the literature regarding "on-field management by the dentist" for sports dental injuries.

Hence the aim of this article is to provide collective information regarding the immediate management of dental injuries occurring on the field' by the dental professional. 
Sports injuries have been discussed as follow,

1. Intra-oral teeth and periodontium-related injuries.

2. Intra-oral lip, tongue-related injuries.

3. Extra-oral injuries.

\section{Intraoral Teeth and Periodontium Related Injuries}

Intraoral dental injuries can be classified as hard tissue and periodontal. The 1992 WHO-Andreasen system is the commonly utilized system for the classification of the dental hard tissues and pulp and the periodontium. It is subdivided into eight descriptive classes of hard tissue injuries and six descriptive classes of injuries to the periodontium. ${ }^{5,6}$

AVULSION: It can be described as complete displacement of a tooth from the socket owing to trauma.

First aid and management on the field by the dentist.

- Pick up the tooth without touching the root part. Check for the dentition. Deciduous teeth should not be reimplanted. Treatment for avulsion is carried out only for permanent dentition.

- Dentist should gently clean the tooth with cold water if it is dirty (max $10 \mathrm{~s})$ and reposition it. After it is placed back to its original position, bite on a handkerchief to keep the tooth in position.

- Ideal period for replantation of an avulsed tooth is considered to be within 5 to 10 minutes after exfoliation. As more periods are elapsed after the tooth is out of the socket, the risk of ankylosis increases and which is the scenario in most cases. If the extraoral dry time is more than 20 minutes, the successful reimplantation is less likely to happen, and if the time is surpassed 60 minutes, there is a very negligible chance of successful reimplantation.

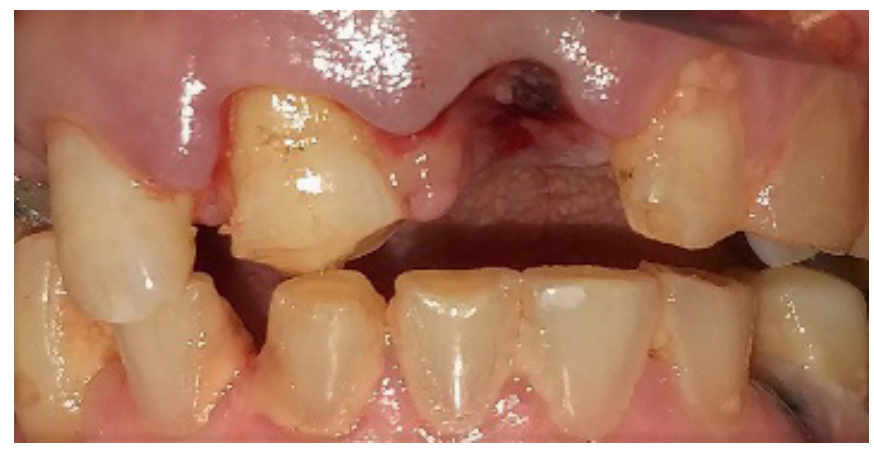

Figure 1: Avulsion

Table 1: WHO-Andreasen classification of dental and periodontal traumas

\begin{tabular}{ll}
\hline Hard tissue injuries & Periodontal injuries \\
\hline Infraction & Concussion \\
Enamel fracture & Subluxation \\
Enamel and dentin fracture & Avulsion \\
Enamel, dentin fracture involving the pulp & Intrusion \\
Root fracture & Extrusion \\
Alveolar bone fracture & \\
\hline
\end{tabular}

To avoid damage to the periodontal ligaments, the root surface should not be touched with fingers and should not be cleaned aggressively. ${ }^{7}$

- If it is not possible to reimplant the avulsed tooth immediately, it should be kept and carried in a storage medium, in preference order of,

- The storage of any remnant of the tooth is also extremely beneficial to the success of functional and esthetical replacement as it keeps the periodontal tissue viable, which is essential for the reattachment of the PDL fibers. ${ }^{8,9}$

- If the tooth is contaminated due to debris, then the tooth should be held by its crown and should be cleaned with water or normal saline; only after properly orienting the position of the crown by observing the adjacent teeth, it should be reimplanted in the empty socket. ${ }^{8,10}$

- Once replanted, the tooth may be splinted and kept in a stable position using a temporary cement material or adhesive tape followed by systemic antibiotics for proper healing of periodontal and pulpal tissue. ${ }^{11}$

- Players who have replantation and splinting of avulsed teeth should wait at least 2 to 4 weeks to return to the field and are advocated the use of mouthguard and face mask for protection. ${ }^{8,12}$

- After checking the tetanus status, a recommendation for taking as booster vaccinations are taken into consideration.

"Adding my personal experience during my school days, while playing cricket with a season ball which had cost to our wicketkeeper a permanent loss of both maxillary central incisors after trauma to the teeth with the ball, while wicket-keeping behind the stumps as the keeper was not wearing a helmet. If I had known about the reimplantation procedure, we could have saved the teeth of the wicket-keeper".

\section{Displacement/Luxation of Tooth}

If a tooth is loosened or pushed out of position from the socket. I have mostly seen after mild blunt trauma to the anterior segment of teeth. There can be lateral luxation, extrusion, intrusion of teeth.

\section{On-field Management}

The displaced tooth should be gently moved and guided by the dentist to its normal position by applying mild pressure.

Application of cold compress over an oedematous area, local anesthesia may be given ${ }^{13}$.

\section{Crown Fracture}

Depending on the involvement of the enamel, dentin and pulp crown fractures can be classified as ${ }^{14}$,

\begin{tabular}{lll}
\hline $\begin{array}{l}\text { Enamel } \\
\text { infraction }\end{array}$ & $\begin{array}{l}\text { Incomplete fracture of } \\
\text { enamel without loss of } \\
\text { tooth structure. }\end{array}$ & $\begin{array}{l}\text { No immediate } \\
\text { treatment required but } \\
\text { referral to the dentist } \\
\text { must be given }\end{array}$ \\
$\begin{array}{lll}\text { Enamel } \\
\text { fractures }\end{array}$ & $\begin{array}{l}\text { Fracture of only the } \\
\text { outer layer of the tooth } \\
\text { (the enamel). }\end{array}$ & $\begin{array}{l}\text { No immediate } \\
\text { treatment required but } \\
\text { referral to the dentist } \\
\text { must be given }\end{array}$ \\
\hline
\end{tabular}




\begin{tabular}{lll}
\hline $\begin{array}{l}\text { Enamel and } \\
\text { dentin fracture }\end{array}$ & $\begin{array}{l}\text { Fracture of outer } \\
\text { enamel and an inner } \\
\text { dentinal layer of the } \\
\text { tooth. A tooth may be } \\
\text { sensitive to cold or air. }\end{array}$ & $\begin{array}{l}\text { If the presence of mild } \\
\text { sensitivity, capping } \\
\text { can be performed on } \\
\text { the field with readily } \\
\text { available calcium } \\
\text { hydroxide cement. }\end{array}$ \\
$\begin{array}{ll}\text { Enamel, } \\
\text { dentin fracture } \\
\text { involving the } \\
\text { pulp }\end{array}$ & $\begin{array}{l}\text { Exposure of the pulp } \\
\text { means it has bacterial } \\
\text { contamination, which } \\
\text { can lead to necrosis } \\
\text { of the pulp and/or } \\
\text { abscess. The tooth may } \\
\text { have the appearance } \\
\text { of bleeding or may } \\
\text { display a small red } \\
\text { spot. }\end{array}$ & $\begin{array}{l}\text { calcium hydroxide is } \\
\text { recommended until } \\
\text { definitive dental care is }\end{array}$ \\
achieved.
\end{tabular}

\section{Description On-field treatment}

\section{Root Fracture}

- A horizontal impact may lead to root fracture, which the mobility of the fractured segment can determine.

- Bleeding from the teeth is noted in case of root fractures. Efforts should be taken to slow down and stop the bleeding by applying pressure.

- Depending on the location of the root fracture, treatment varies.

- Referral to the dental clinic should be given for definitive treatment. $^{15}$

\section{Other Intraoral InJURies}

\section{LIP, Tongue Injuries}

- Lip and intraoral injuries, including injuries of the tongue, have been reported to make up almost $25 \%$ of all sportsrelated maxillofacial injuries.

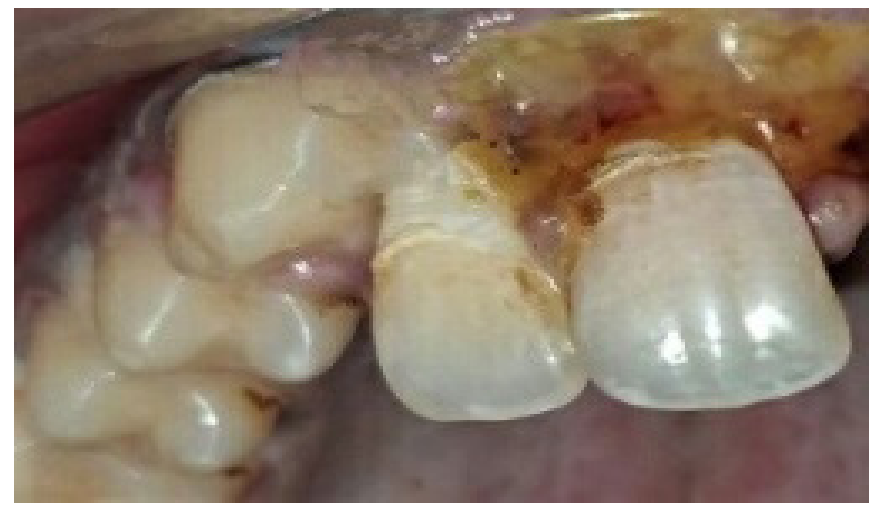

Figure 2: Luxation of central and lateralincisor.

Table 2: A storage medium

Hank's Balanced Salt Solution

Cold milk

saliva of the patient itself or inside the patient's cheek

Saline

Water
- After the lip, tongue, or teeth, the athlete's overall status should be evaluated. Vitals, breathing, and neurological status should be checked.

- Simple lacerations may stop bleeding after applying pressure or may be closed with sterile dressings, tissue glues. The deep lacerations with continuous nonstop bleeding should be immediately referred for surgical interventions.

- Apply pressure to the lacerations of the lip or tongue by covering the wound with the gauze until the blood flow slows down. The wound should be examined, cleaned, and a decision for suture placement should be made.

- Most studies recommend that adhesive should be used for superficial cuts smaller than $4 \mathrm{~cm}$ while sutures are used for deeper and larger lacerations. ${ }^{16}$

\section{EXTRAORAL INJURIES}

\section{Facial Abrasions and Contusion}

- Mild facial abrasions, which are superficial, should be cleaned and washed for removal of debris, antiseptics should be applied, most abrasions will heal in a few days.

- Deep, severely bleeding wounds should be immediately referred for surgical interventions. Contusions are one of the most common soft-tissue injuries in the athlete, ranging from mild to very severe.

- Most of the time contusions heal on their own within few weeks; ice packs during the initial hours help to reduce the signs and symptoms of inflammation in the localized area of the trauma. ${ }^{16,17}$

\section{Oral and Maxillofacial Fractures}

- Post severe blow to the facial structures may lead to various fractures depending on the location of the blow and the direction of the impact. Hematomas and intraoral lacerations usually indicate significant underlying injury such as maxillary or zygomaticomaxillary fractures.

- Severe injury may lead to damage to the underlying structures, such as nerve, muscle, and bone, resulting in serious cosmetic defects or loss of functions if not treated.

- The movements of facial expression are tested by movements of the eyebrows, eyes, smile, forehead. A deficit in any of these would suggest injury to one of the branches of the facial nerve. Inability to open, trismus or pain in the cheek or near the ear suggests fracture and injury to the zygomatic complex or the zygomatic arch.

- General examination and palpation of orofacial structures are performed. Inspect for hematomas, bimanual palpation of maxilla and over mandible is done. Mobility, crepitus, or step deformity along with tenderness may suggest a fracture of oral and maxillofacial complex. An intraoral examination and palpation should be performed. Dentoalveolar fractures should be referred to the surgeon for reduction.

- Local application of icepacks over the hematomas, analgesics should be prescribed. ${ }^{17-19}$ 
- In case of unconsciousness after trauma, the primary moto should be emergency care; dental treatment should be performed at the dental clinic after gaining consciousness.

\section{TMJ Injuries}

- Trauma to the 0mandible may lead to dislocations, acute capsulitis.

- TMD trauma's common signs and symptoms include jaw ache, earache, headache, decreased range of motion, and clicking and crepitus of the joint.

- Self-limiting dislocations can be taken care of easily, and they don't require any further management.

- TMJ dislocations involving a non-self-limiting displacement of the condyle can be taken care of by manually guiding the jaw back to the position by giving downward, backward and upward pressure to the mandible by placing the thumb over the occlusal surface of molars bilaterally and supporting the base of the mandible with remaining fingers ${ }^{15}$.

\section{Emergency Dental Kit for Sport EVENTS ${ }^{15}$}

A dental emergency kit should be kept ready on the field with the following items,

Gloves, mask, Mouth mirror, Probe.
Torch, scissor, suture material, needle, normal saline, wire cutter, pliers.
Zinc oxide eugenol cement, calcium hydroxide cement/pulp
capping agent, mixing pad, spatula.
Gauze piece, cotton, iodine, antiseptic liquid.
Anaesthetic spray, painkiller spray, local anaesthesia.
The save-a-tooth solution, cold milk.

\section{Conclusion}

Even though many awareness modalities have been implemented for sportsmen, coaches regarding sports dental injuries, due to lack of knowledge about dental anatomy to the layman, only a dentist can provide proper immediate dental management, which will lead to a better prognosis.

Most of the sports dental injuries can be taken care of by providing proper immediate treatment and care, and hence it should be mandatory for sports events to appoint a dentist 'on the field for management of sports injuries, which not commonly implemented in India.

Implanting a mobile dental van/clinic with a well-equipped dental setup in the vicinity of the sports events can be considered to reduce the time lapse after trauma.

The sports events and the schools where children play outdoor sports on a regular basis can also require immediate dental help. Hence it should be mandatory for schools to have a dentist on call.

At present many sporting events around the globe are organized without appointing a dentist on the field. It is very important to immediately treat sports-related injuries for a better prognosis and prevent future permanent complications.
Even though 'on field' immediate treatment for sports injuries is carried out, further dental referral should be made mandatory for evaluation and follow-ups.

\section{REFERENCES}

1. Sports dentistry: Role of dentist in protecting a winning smile

2. Assessment of knowledge, attitude, and practices toward orofacial injuries among students engaged in sports from Davangere city: A cross sectional survey Veeresh DJ, Apoorva Shukla, Abhirami Srikanth1, Anshul Jain1 , Bishakha Lalani1

3. Polmann H, Melo G, Conti Réus J, Domingos FL, de Souza BD, Padilha AC, Duque TM, Porporatti AL, Flores-Mir C, De Luca Canto G. Prevalence of dentofacial injuries among combat sports practitioners: A systematic review and meta-analysis. Dental Traumatology. 2020 Apr;36(2):124-40.

4. Castaldi CR. Sports Dentistry. ASDC journal of dentistry for children. 1989;56(3):236.

5. Traumatic Dental Injuries Resulting from Sports Activities; Immediate Treatment and Five Years Follow-Up: An Observational Study

6. Andreasen JO, Lauridsen E, Gerds TA, Ahrensburg SS. Dental Trauma Guide: A source of evidence-based treatment guidelines for dental trauma. Dent Traumatol 2012; 28(5): 345-350. [http://dx.doi.org/10.1111/j.1600-9657.2011.01059_1.x] [PMID: 22994505]

7. Andersson L, Andreasen JO, Day P, et al. International Association of Dental Traumatology guidelines for the management of traumatic dental injuries: 2. Avulsion of permanent teeth. Dent Traumatol. 2012;28:88-96.

8. American Academy of Pediatric Dentistry. Guideline on Management of Acute Dental Trauma. http://www.aapd.org/media/policies guidelines/g_trauma.pdf. Accessed February 12, 2012

9. Emerich K, Kaczmarek J. First aid for dental trauma caused by sporting activities. Sports Med. 2010;40:361-366.

10. Rosenberg H, Rosenberg H, Hickey M. Emergency management of a traumatic tooth avulsion. Ann Emerg Med. 2011;57:375-377.

11. Spinas E, Savasta A. Prevention of traumatic dental lesions: cognitive research on the role of mouth guards during sport activities in paediatric age. Eur J Paediatr Dent. 2007;8:193-198.

12. Huffman EA, Yard EE, Fields SK, et al. Epidemiology of rare injuries and conditions among United States high school athletes during the 2005-2006 and 2006-2007 school years. J Athl Train. 2008;43:624-630.

13. Bakarčić D, Hrvatin S, Maroević M, IvančićJokić N. First aid management in emergency care of dental injuries-knowledge among teachers in Rijeka, Croatia. Acta ClinicaCroatica. 2017 Mar 1;56(1.):110-6.

14. Josell SD, Abrams RG. Managing common dental problems and emergencies. Pediatric Clinics of North America. 1991 Oct 1;38(5):1325-1342.

15. Smith WS, Kracher CM. Sports-related dental injuries and sports dentistry. Dent Assist. 1998 May 1;67(3):12-126.

16. Physiopedia contributors. Facial and Dental Injuries in Sports Medicine [Internet]. Physiopedia, ; 2020 Oct 17, 16:12 UTC [cited 2021 Mar 28].

17. Kaufman BR, Heckler FR. Sports-related facial injuries. Clinics in sports medicine. 1997 Jul 1;16(3):543-562.

18. 1. Le Fort R Experimental study of fractures of the upper jaw: I and 11. Revue Chirurgi.

19. 2. Le Fort R Experimental study of fractures of the upper jaw: 111 Revue Chirurgi de Paris. 